\title{
ASSÉDIO MORAL COMO INIMIGO INVISÍVEL NO TRABALHO DO ENFERMEIRO
}

\section{MORAL HARASSMENTAS AN INVISIBLE ENEMY IN THE NURSES' WORK
ASEDIO MORAL COMO INIMIGO INVISIBLE EN EL TRABAJO DEL ENFERMERO

\author{
Diego Rafael Pereira Limoeiro ${ }^{1}$, Jorge Luiz Lima da Silva ${ }^{2}$, Gilvania Barreto Feitosa Coutinho ${ }^{3}$, Gabriela Lima \\ dos Santos ${ }^{4}$, João Victor Jaegger de França ${ }^{5}$, Edmilson Teófilo Monteiro ${ }^{6}$
}

\section{RESUMO}

Objetivo: descrever os principais aspectos do assédio moral no trabalho do enfermeiro. Método: trata-se de revisão sistemática da literatura, dos últimos 5 anos. Foram analisados 11 artigos científicos dentre outros documentos. Resultados: constatou-se que os principais aspectos do assédio moral envolvidos no labor do enfermeiro são os de cunho organizacional, em decorrência da estrutura hierárquica rígida presente em seu ambiente laboral, abrangendo relações sociolaborais e normativas, que vão desde a constituição federal até a lei do exercício profissional. Conclusão: o estudo demonstrou a importância do papel do enfermeiro, respeitando sua individualidade quanto gestor e a dignidade da pessoa humana, garantindo um ambiente de trabalho livre de danos; e, consequentemente, o bem-estar geral para a comunidade.

Descritores: assédio não sexual; saúde do trabalhador; enfermagem do trabalho; e equipe de enfermagem.

\section{ABSTRACT}

Objective: to describe the main aspects of moral harassment in the work of the nurse. Method: this is a systematic review of the literature of the last 5 years. Eleven scientific articles were analyzed, among other documents. Results: it was verified that the main aspects of moral harassment involved in the work of nurses are those of an organizational nature, due to the rigid hierarchical structure present in their work environment, covering social and normative relations, ranging from the federal constitution to the law of professional practice. Conclusion: the study demonstrated the importance of the role of nurses, respecting their individuality as manager and the dignity of the human person, guaranteeing a work environment free of damages and consequently the general welfare for the community.

Descriptors: harassment non-sexual; occupational health; occupational health nursing; and nursing team.

\footnotetext{
${ }^{1}$ Pós-Graduado em Enfermagem do Trabalho pela Universidade Federal Fluminense - UFF- RJ.

2 Doutor em Saúde Pública pela Escola Nacional de Saúde Pública Ensp / Fiocruz. Professor do depto. Materno Infantil e Psiquiatria da Universidade Federal Fluminense - UFF.

${ }^{3}$ Mestre em Saúde Pública pela Escola Nacional de Saúde Pública/Fiocruz- RJ.

${ }^{4}$ Acadêmica de Enfermagem da Universidade Federal Fluminense.

${ }^{5}$ Acadêmico de Enfermagem da Universidade Federal Fluminense.

${ }^{6}$ Acadêmico de Enfermagem da Universidade Federal Fluminense.
} 


\section{RESUMEN}

Objetivo: describir los principales aspectos del acoso moral en el trabajo del enfermero. Método: se trata de una revisión sistemática de la literatura, de los últimos 5 años. Se analizaron 11 artículos científicos entre otros documentos. Resultados: se constató que los principales aspectos del acoso moral involucrados en la labor del enfermero son los de cuño organizacional, en consecuencia, de la estructura jerárquica rígida presente en su ambiente laboral, abarcando relaciones sociolaborales y normativas, que van desde la constitución federal hasta la ley del ejercicio profesional. Conclusión: el estudio demostró la importancia del papel del enfermero, respetando su individualidad como gestor y la dignidad de la persona humana, garantizando un ambiente de trabajo libre de daños y consecuentemente el bienestar general para la comunidad.

Descriptores: acoso no sexual; salud laboral; enfermería del trabajo; e grupo de enfermería.

\section{INTRODUÇÃO}

O que motivou o início da pesquisa foi a pungente recorrência do tema sobre assédio moral e a complexidade em caracterizar a etiologia, por sua subjetividade e abrangência no âmbito da enfermagem, principalmente no que tange o cotidiano laboral do enfermeiro, visto que é responsável por gerir cuidados e exercer papel fundamental perante a equipe de enfermagem.

Segundo Barreto ${ }^{1}$, "assédio moral é um tema complexo cujo conceito em si é polissêmico". Pela complexidade da etiologia, principalmente por sua subjetividade e abrangência, tornou-se tema recorrente, posto em evidência pela comunidade trabalhadora e acadêmica ganhando repercussão midiática. Em 1976, o psiquiatra norte americano Carroll $\mathrm{M}$. Brodsky escreveu o livro: "o assediado Trabalhador", utilizando-se do termo harassment emprestado do conceito de assédio sexual ${ }^{2}$, mas o tema só ganhou notoriedade, oito anos depois, quando em 1984, o psicólogo Alemão Heinz Leymann iniciou pesquisas baseadas em evidências chamadas à época de psicoterror. Além de utilizar a palavra mobbing, o autor escolheu esse termo para distinguir esta forma de violência psicológica em adultos e bullying para atividades entre adolescentes, na escola ${ }^{3}$. Em 1998 na França, a psiquiatra e psicoterapeuta familiar, Marrie France Hirigoyen publica: Harcèlement moral: La violence perverse au quotidien, que se tornou um best-seller, traduzido em 27 línguas. ${ }^{2}$

No Brasil, a especialista em medicina do trabalho e doutora em psicologia social pela PUC-SP, Margarida Maria Silveira Barreto foi precursora dos estudos sobre assédio moral no ambiente de trabalho, tendo como obra principal: "violência, saúde e trabalho" (uma jornada de humilhações), onde em 1996 a autora, 
inicia projeto de pesquisa com 2.072 trabalhadores de 97 empresas de grande, médio e pequeno porte, onde a maioria dos entrevistados apresentou histórias de humilhação e constrangimentos no trabalho. Dessa maneira, pode-se observar que, historicamente, o conceito foi batizado com nomenclaturas diferentes, porém descrevem o mesmo tipo de violência no trabalho, que vem se propagando até os dias atuais. Não visto como doença, o assédio moral é tratado como risco psicossocial emergente de barreiras invisíveis, não materiais e intocáveis, sendo assim, por ser de domínio subjetivo, difícil de caracterizálo. ${ }^{4}$

Pode-se ainda, defini-lo como exposição dos trabalhadores a situações humilhantes e constrangedoras, repetitivas e prolongadas, durante a jornada de trabalho, e no exercício de suas funções, sendo mais comuns em relações hierárquicas autoritárias e assimétricas em que predominam condutas negativas, relações desumanas e éticas de longa duração, de um ou mais chefes dirigida a um ou mais subordinado(s), desestabilizando a relação da vítima com o ambiente de trabalho e a organização, forçando-os a desistirem do emprego. ${ }^{4}$

A problemática atinge trabalhadores e trabalhadoras de todas as classes, porém são destacados, neste estudo, os profissionais de enfermagem, sobretudo o enfermeiro, por ser a principal referência da equipe. Todavia as agressões, muitas vezes vão além das relações interpessoais, mas dizem respeito à organização do trabalho, principalmente quando existe uma lacuna entre o trabalho prescrito, e o trabalho realizado.

O trabalho em saúde é essencial para a vida humana, é da esfera da produção imaterial, que se completa no ato da sua realização. As atividades desse setor são de fundamental importância para a vida em sociedade e têm função de satisfazer as condições sociais de sobrevivência.

A Organização Mundial de Saúde (OMS) define violência como o uso intencional da força física ou do poder, real ou em ameaça, contra si próprio, contra outra pessoa, ou contra um grupo ou uma comunidade, que resulte ou tenha grande possibilidade de resultar em lesão, morte, dano psicológico, deficiência de desenvolvimento ou privação ${ }^{5}$. Inseridos nesse contexto, o enfermeiro, encontra-se em situação de vulnerabilidade vez que está exposto a todas as condições de assédio, que se apresentam das seguintes formas: horizontal, praticado por pessoas hierarquicamente do mesmo nível que a vítima; vertical ascendente, quando um superior é assediado por um ou vários subordinados, geralmente por não se 
adequarem aos padrões implantados pelo superior; vertical descendente, quando o chefe subordina, de forma autoritária o empregado; e o misto, aquele que envolve $\mathrm{o}$ assediador vertical, $\mathrm{o}$ assediador horizontal e a vítima. ${ }^{6}$

A exposição dos enfermeiros, para caracterização do assédio moral em seu ambiente laboral, não pode ser analisada sob a ótica de situações conflituosas isoladas, existem variáveis como a continuidade e o período com que se dão essas exposições, podendo causar ou agravar muitos transtornos psicopatológicos, psicossomáticos e comportamentais. Porém, ainda não se tem estimativa estatística de quantos trabalhadores sofreram algum tipo de consequência.

Assim, mediante ao exposto, a questão de pesquisa desse estudo visa responder: quais são os principais aspectos do assédio moral relacionado ao labor do enfermeiro? Para responder tal questão, foi definido o objetivo de descrever os principais aspectos do assédio moral no trabalho do enfermeiro.

\section{MÉTODO}

Trata-se de estudo descritivo que se deu por meio de revisão sistematizada de literatura. $\mathrm{O}$ estudo foi realizado a partir da leitura de obras produzidas entre os anos de 2010 a 2016. A busca de informações foi realizada de maio a novembro de 2016 e utilizados para a realização desta pesquisa: 1 livro, 1 cartilha sobre assédio moral disponível no site do Ministério da Saúde, 11 artigos científicos, 1 tese de doutorado, 1 nota técnica e 1 editorial.

A investigação aconteceu nas bases BVS, Lilacs, Medline e Scielo, usando como critério os textos completos no idioma português. Foram utilizados os descritores: assédio moral, saúde do trabalhador, enfermagem.

A princípio foram utilizados como critério de exclusão a temática apresentada no resumo dos textos, artigos com título que divergiam do tema, e a repetição dos artigos nas bases pesquisadas anteriormente; empregando, ainda, o ano de publicação como critério de exclusão, foram eliminados artigos anteriores a 2010. Para o descritor saúde do trabalhador, foram utilizados como critério de escolha os artigos que tinham no seu assunto principal a enfermagem. Após a leitura do título e resumo desses materiais, foram selecionadas 16 produções, dentre os quais 13 artigos. Em seguida, a leitura dos principais achados proporcionou a seleção de 11 artigos. Vale destacar que a nota técnica, foi de extrema importância para que se pudesse entender a etimologia da palavra assédio moral, sua polissemia e incidência ao longo dos anos. 


\section{RESULTADOS}

Nesta seção, são apresentadas as obras com seus principais síntese dos principais achados das obras capturadas, segundo as diretrizes do método empregado neste estudo.

achados para posterior discussão. No quadro, a seguir, encontra-se a

Quadro 1: Artigos escolhidos envolvendo a temática, após aplicação de critérios de exclusão, Niterói, 2016.

\begin{tabular}{|c|c|c|c|}
\hline $\begin{array}{l}\text { AUTOR (ES), PERIÓDICO, } \\
\text { TÍTULO, ANO, BASE VIRTUAL }\end{array}$ & TIPO DE ESTUDO & OBJETIVO GERAL & RESUMO DOS PRINCIPAIS ACHADOS \\
\hline $\begin{array}{l}\text { Barreto e Heloani (2015). } \\
\text { Violência, saúde e trabalho: A } \\
\text { intolerância e o assédio moral nas } \\
\text { relações laborais. } \\
\text { Serv. Soc. Soc. Lilacs. }\end{array}$ & Descritivo & $\begin{array}{l}\text { Analisar a intolerância e suas manifestações } \\
\text { nas sociedades modernas, em particular nos } \\
\text { espaços de trabalho, expressado por meio de } \\
\text { atitudes discriminatórias, irônicas, doentias e } \\
\text { recorrentes que configuram o assédio moral. }\end{array}$ & $\begin{array}{l}\text { O assédio moral deve ser compreendido } \\
\text { como um risco não visível derivado dos } \\
\text { modos de organizar e administrar o trabalho; } \\
\text { das condições laborais estabelecidas e vetores } \\
\text { psicossociais assumidos; da cultura } \\
\text { organizacional que induz a reproduzir as } \\
\text { fofocas e boatos pelo "ouvir dizer" do senso } \\
\text { comum, contando com total tolerância dos } \\
\text { gestores a essa nefasta cultura do "disse que } \\
\text { disse". }\end{array}$ \\
\hline $\begin{array}{l}\text { Fontes e cols. (2013). } \\
\text { Fatores associados ao assédio moral } \\
\text { no ambiente laboral do enfermeiro. } \\
\text { Rev. Latino-Am. Enfermagem. } \\
\text { Medline. }\end{array}$ & Descritivo exploratório & $\begin{array}{l}\text { Identificar enfermeiros vítimas de assédio } \\
\text { moral no trabalho e fatores associados. }\end{array}$ & $\begin{array}{l}\text { O estudo identificou enfermeiros vítimas e } \\
\text { determinou fatores condicionantes do assédio } \\
\text { moral, como por exemplo: ter filhos, atuar } \\
\text { nas unidades de saúde pública, trabalhar na } \\
\text { instituição por período de } 1 \text { a } 3 \text { anos, } \\
\text { enfrentar atualmente condutas de assédio } \\
\text { moral no trabalho e se perceber assediado } \\
\text { moralmente. }\end{array}$ \\
\hline $\begin{array}{l}\text { Costa e cols. (2015). } \\
\text { Produção científica acerca do } \\
\text { assédio moral em dissertações e teses } \\
\text { no cenário brasileiro. } \\
\text { Rev Esc. Enferm USP. 2015. Lilacs. }\end{array}$ & Bibliométrico & $\begin{array}{l}\text { Analisar a produção científica acerca do } \\
\text { assédio moral em dissertações e teses no } \\
\text { Brasil. }\end{array}$ & $\begin{array}{l}\text { O estudo ressalta a preocupação de } \\
\text { pesquisadores no cenário brasileiro acerca do } \\
\text { assédio moral, buscando conferir maior } \\
\text { visibilidade no meio acadêmico, destacando } \\
\text { as áreas do conhecimento com maior } \\
\text { quantidade de publicações (Psicologia, } \\
\text { direito e enfermagem), evidenciando o amplo }\end{array}$ \\
\hline
\end{tabular}




\begin{tabular}{|c|c|c|c|}
\hline & & & $\begin{array}{l}\text { desenvolvimento da temática em virtude da } \\
\text { sua variedade e abrangência. }\end{array}$ \\
\hline $\begin{array}{l}\text { Lima e Sousa (2015). } \\
\text { Violência psicológica no trabalho de } \\
\text { enfermagem. } \\
\text { Rev Bras Enferm. Lilacs. }\end{array}$ & Descritivo exploratório & $\begin{array}{l}\text { Investigar e caracterizar práticas de } \\
\text { violência psicológica intraequipe, pacientes, } \\
\text { acompanhantes e outros profissionais com } \\
\text { os trabalhadores de enfermagem da rede } \\
\text { hospitalar pública de Caxias, no Estado do } \\
\text { Maranhão. }\end{array}$ & $\begin{array}{l}\text { O estudo mostra que a categoria que mais } \\
\text { sofre com a violência no trabalho são os } \\
\text { enfermeiros, onde sofrem violência verbal e } \\
\text { assédio moral. Os maiores agressores são } \\
\text { pacientes e acompanhantes seguidos pelos } \\
\text { colegas de trabalho. Destaca a inércia dos } \\
\text { gestores e empregadores no que se refere às } \\
\text { medidas de controle e prevenção da } \\
\text { violência. }\end{array}$ \\
\hline $\begin{array}{c}\text { Soares (2012). } \\
\text { As origens do conceito de assédio } \\
\text { moral no trabalho. } \\
\text { Rev. bras. Saúde ocup. Lilacs } \\
\end{array}$ & Nota técnica & $\begin{array}{l}\text { Citar as origens do conceito de assédio } \\
\text { moral no trabalho }\end{array}$ & $\begin{array}{l}\text { O autor aborda a polissemia que envolve o } \\
\text { termo assédio moral, seu processo } \\
\text { multicausal e suas nuances na saúde física e } \\
\text { mental. }\end{array}$ \\
\hline $\begin{array}{l}\text { Gouveia e cols. (2012). } \\
\text { Assédio moral: compreensão de } \\
\text { estudantes de enfermagem. } \\
\text { Rev. Enferm. UERJ. Medline. }\end{array}$ & Descritivo exploratório & $\begin{array}{l}\text { Investigar como os estudantes de } \\
\text { enfermagem compreendem o assédio moral. }\end{array}$ & $\begin{array}{l}\text { O estudo aponta que o entendimento dos } \\
\text { discentes inseridos no estudo, está em } \\
\text { consonância com a literatura, porém } \\
\text { características definidoras do assédio moral e } \\
\text { relacionadas ao assediador, ainda são } \\
\text { insipientes por parte dos discentes. }\end{array}$ \\
\hline $\begin{array}{l}\text { Andrade e cols. (2015). } \\
\text { Assédio moral na atenção básica } \\
\text { segundo os profissionais de } \\
\text { enfermagem. } \\
\text { Trab. Educ. Saúde. Lilacs. }\end{array}$ & Descritiva exploratória & $\begin{array}{l}\text { Investigar como os profissionais de } \\
\text { enfermagem compreendem o assédio moral, } \\
\text { bem como identificar essas situações } \\
\text { vivenciadas pelos profissionais dessa área, } \\
\text { suas causas e consequências para a saúde } \\
\text { desses trabalhadores. }\end{array}$ & $\begin{array}{l}\text { O estudo ressalta que o assédio moral } \\
\text { acontece de diversas formas e está presente } \\
\text { nas relações de trabalho da enfermagem e } \\
\text { evidencia que é disseminado entre } \\
\text { enfermeiros e técnicos de enfermagem com } \\
\text { prevalência do tipo de assédio moral } \\
\text { descendente, destacando as situações de } \\
\text { humilhação, constrangimento e perseguições } \\
\text { de forma repetitiva, desestabilizando o } \\
\text { equilíbrio físico e emocional da vitima. Além } \\
\text { de salientar o desconhecimento da prática por } \\
\text { parte de dos profissionais de enfermagem. }\end{array}$ \\
\hline $\begin{array}{c}\text { Pereira (2011). } \\
\text { Assédio moral nas relações de } \\
\text { trabalho de docentes-enfermeiros: }\end{array}$ & Tese de doutorado & $\begin{array}{l}\text { Identificar a ocorrência do assédio moral em } \\
\text { docentes-enfermeiros; descrever os tipos de }\end{array}$ & $\begin{array}{l}\text { A pesquisa revelou a elevada ocorrência do } \\
\text { assédio moral no trabalho dos docentes- } \\
\text { enfermeiros. Identificadas ainda organizações }\end{array}$ \\
\hline
\end{tabular}

Rev Enferm Atenção Saúde [Online]. Jul/Dez 2017; 7(1):174-185

ISSN 2317-1154 


\begin{tabular}{|c|c|c|c|}
\hline $\begin{array}{l}\text { sob a ótica da organização do } \\
\text { trabalho. Lilacs. }\end{array}$ & & $\begin{array}{l}\text { assédio moral no trabalho que ocorrem entre } \\
\text { os docentes-enfermeiros; analisar do ponto } \\
\text { de vista da organização do trabalho a relação } \\
\text { dessa organização com a ocorrência do } \\
\text { assédio moral no trabalho entre os docentes- } \\
\text { enfermeiros e discutir as possíveis } \\
\text { repercussões do assédio moral no trabalho } \\
\text { na ambiência laboral e na saúde desses } \\
\text { profissionais. }\end{array}$ & $\begin{array}{l}\text { de trabalho exigentes, competitivas e } \\
\text { burocratizadas contribuindo para a ocorrência } \\
\text { elevada do assédio moral. Os tipos mais } \\
\text { evidenciados foram: vertical descendente e } \\
\text { ascendente; horizontal. A maior ocorrência } \\
\text { foi do tipo vertical descendente. As } \\
\text { instituições devam proporcionar meios de } \\
\text { divulgação do assédio moral, objetivando } \\
\text { sensibilizar e conscientizar os trabalhadores } \\
\text { sobre o tema, } \\
\text { permitindo-lhes reflexão sobre a magnitude } \\
\text { do assédio moral nas relações de trabalho e } \\
\text { suas repercussões. }\end{array}$ \\
\hline $\begin{array}{c}\text { Santos e cols. (2014). } \\
\text { Assédio moral no âmbito de } \\
\text { enfermagem: revisão integrativa da } \\
\text { literatura. } \\
\text { Cogitare Enferm. Lilacs }\end{array}$ & Revisão integrativa da literatura & $\begin{array}{l}\text { Sintetizar a produção científica acerca da } \\
\text { prática do assédio moral no âmbito da } \\
\text { Enfermagem, em periódicos disponíveis } \\
\text { online, no período de } 2005 \text { a novembro de } \\
2012 \text {. }\end{array}$ & $\begin{array}{l}\text { O estudo constatou que a discussão acerca do } \\
\text { assédio moral, está em desenvolvimento } \\
\text { pleno, além de mostrar a prevalência do } \\
\text { assédio moral no âmbito da enfermagem ter } \\
\text { aumentado expressivamente, acarretando } \\
\text { consequências psicológicas. }\end{array}$ \\
\hline $\begin{array}{c}\text { Lisboa (2010) } \\
\text { Assédio moral no trabalho de } \\
\text { enfermagem. Cogitare Enferm. } \\
\text { Lilacs. } \\
\end{array}$ & Editorial & $\begin{array}{l}\text { Refletir sobre a temática, através das } \\
\text { publicações recentes e seus principais } \\
\text { precursores. }\end{array}$ & $\begin{array}{l}\text { A autora destaca que resistir, dar visibilidade, } \\
\text { denunciar e documentar situações de assédio } \\
\text { morais, são formas de lutar contra esse tipo } \\
\text { de violência no trabalho. }\end{array}$ \\
\hline $\begin{array}{l}\text { Glina e Soboll (2012). } \\
\text { Intervenções em assédio moral no } \\
\text { trabalho: uma revisão de literatura. } \\
\text { Rev. bras. Saúde ocup. Lilacs. }\end{array}$ & Pesquisa bibliográfica & $\begin{array}{l}\text { Identificar e sistematizar os métodos de } \\
\text { intervenção em assédio moral. }\end{array}$ & $\begin{array}{l}\text { O estudo destaca o papel da alta gerencia a } \\
\text { fim de planejar, a partir de decisões } \\
\text { conscientes, intervenções necessárias, } \\
\text { levando em consideração que intervenções } \\
\text { pontuais e isoladas não funcionam dada a } \\
\text { natureza complexa, multidimensional, } \\
\text { relacional e processual do assédio moral. }\end{array}$ \\
\hline $\begin{array}{l}\text { Cahú e cols. (2014). } \\
\text { Situações de assédio moral } \\
\text { vivenciadas por enfermeiros no } \\
\text { ambiente de trabalho. } \\
\text { Acta Paul Enferm. Medline. }\end{array}$ & Pesquisa transversal & $\begin{array}{l}\text { Investigar situações de assédio morais } \\
\text { vivenciadas por enfermeiros em seu } \\
\text { ambiente de trabalho. }\end{array}$ & $\begin{array}{l}\text { O estudo define que os enfermeiros } \\
\text { vivenciam situações de assédio moral no } \\
\text { trabalho e que essas, influenciam diretamente } \\
\text { em seu desempenho laboral, na sua saúde e } \\
\text { estado emocional. }\end{array}$ \\
\hline
\end{tabular}




\begin{tabular}{|c|c|c|c|}
\hline $\begin{array}{l}\text { Fontes, Pelloso e Carvalho (2011). } \\
\text { Tendências dos estudos sobre assédio } \\
\text { moral e trabalhadores de } \\
\text { enfermagem. } \\
\text { Rev Gaúcha Enferm. Medline. }\end{array}$ & Revisão integrativa da literatura & $\begin{array}{l}\text { Analisar o conhecimento produzido sobre o } \\
\text { assédio moral na enfermagem, apresentado } \\
\text { em publicações nacionais e internacionais. }\end{array}$ & $\begin{array}{l}\text { O estudo destaca a criação e validação por } \\
\text { enfermeiros, para identificar o assédio moral } \\
\text { no ambiente laboral, que apesar de } \\
\text { identificados, existe uma aceitação e até } \\
\text { reprodução de algumas situações de assédio } \\
\text { moral por parte da cultura organizacional } \\
\text { acarretando o adoecimento e prejuízo de suas } \\
\text { funções. }\end{array}$ \\
\hline $\begin{array}{l}\text { Lima e cols. (2013). } \\
\text { Assédio moral e coping: atuação de } \\
\text { enfermagem no trabalho. } \\
\text { Revista Eletrônica de Enfermagem do } \\
\text { Centro de Estudos de Enfermagem e } \\
\text { Nutrição. Medline. }\end{array}$ & $\begin{array}{l}\text { Pesquisa } \\
\text { bibliográfica }\end{array}$ & $\begin{array}{l}\text { Identificar e descrever como atua a } \\
\text { enfermagem do trabalho no processo de } \\
\text { assédio moral e coping. }\end{array}$ & $\begin{array}{l}\text { O estudo conclui que o assédio moral traz } \\
\text { severas alterações no aspecto laboral e } \\
\text { emocional da vítima, favorecendo o } \\
\text { desenvolvimento de psicopatologias, citando } \\
\text { o importante papel da enfermagem do } \\
\text { trabalho para diminuir e dirimir essas } \\
\text { repercussões. }\end{array}$ \\
\hline
\end{tabular}




\section{DICUSSÃO}

A partir da leitura dos textos selecionados, podem-se observar abaixo os principais aspectos do assédio moral, relacionados ao trabalho dos profissionais, onde os enfermeiros são capazes de exercer atividades, além das privativas, constadas no art. 11 da Lei $\mathrm{N}^{\circ} 7498$ que regulamenta o exercício da enfermagem e dá outras providências. ${ }^{7}$ Com vistas ao importante papel desempenhado pelo profissional e, consequentemente, sua maior exposição às situações de assédio moral, busca entender dentre outros aspectos, porque é a categoria que mais sofre com esse tipo de violência no trabalho. $^{8}$

O assédio moral afeta trabalhadores de diversas áreas; entretanto, pesquisas realizadas em várias partes do Brasil e no mundo, mostram a existência de três nichos distintos, nas áreas de conhecimento, que têm produzido pesquisas referentes ao tema, apesar de destacar, que o ano de 2012, foi o ano com maior número de publicações, 2015 traz maior número de obras, tendo a enfermagem como assunto principal. Entre os artigos publicados recentemente, as áreas de conhecimento que se destacam são a psicologia, direito e enfermagem. ${ }^{9}$

Para que seja entendida a preocupação da enfermagem em relação à problemática, destacam-se alguns aspectos peculiares do cotidiano laboral envolvendo o assédio moral, como por exemplo, as condições organizacionais do trabalho do enfermeiro onde privativamente, é responsável pela direção do órgão de enfermagem, chefia de serviço e de unidade de enfermagem, organizando as atividades técnicas e auxiliares $^{7}$, sendo esse, um dos condicionantes gerador de disputas e problemas de relacionamento entre membros, além da cultura organizacional que induz a reprodução de fofocas e boatos pelo "ouvir dizer" do senso comum, contando com total tolerância dos gestores a essa nefasta cultura do "disse que disse", acarretando repercussões negativas para a saúde do profissional. $^{9,14}$

Estudo apontou outros condicionantes do assédio moral no cotidiano do enfermeiro, como ter filhos, atuar nas unidades de saúde pública, trabalhar na instituição por período de 1 a 3 anos, enfrentar atualmente condutas de assédio moral no trabalho, e se perceber assediado moralmente. ${ }^{15}$ Tornam-se os principais interlocutores entre equipes, visto que é responsável por cuidados diretos a pacientes graves com risco de morte e uso de técnica que exigem conhecimentos de base científica e capacidade de tomar decisões imediatas. $^{7}$

Soma-se a isso, a tensão desenvolvida no contato com pacientes e acompanhantes as quais são favoráveis ao assédio ${ }^{6}$, gerando preocupação entre pesquisadores da área de saúde do trabalhador, que entre outras 
estratégias, buscam a criação e validação de instrumentos, construídos pelos próprios enfermeiros, para identificar o assédio moral, especificamente no contexto da enfermagem. ${ }^{10}$

Embora exista a preocupação dos profissionais com o intuito de identificar, prevenir e dirimir as situações de assédio moral no ambiente de trabalho; as ações, muitas vezes, se dão de forma individualizada, o que não garante o sucesso eficaz do problema, dada a natureza complexa e o caráter multidimensional, relacional e processual do assédio moral no trabalho, com isso fica óbvio que as intervenções pontuais e isoladas pouco surtem efeito. ${ }^{11}$ Dentro dessa realidade, onde o assédio moral é disseminado entre enfermeiros e técnicos de enfermagem com a nítida prevalência do tipo de assédio moral descendente $e^{6,20}$, se torna essencial que as organizações, caminhem lado a lado com a enfermagem do trabalho, a fim de tornar mais eficazes essas abordagens.

Sendo assim, é extremamente importante mudar as formas de gestão no ambiente de trabalho, com o objetivo de desfavorecer a competitividade e integrar os setores assistenciais e de vigilância, com vistas a uma ação $\operatorname{articulada~}^{12}$ na elaboração de medidas efetivas que coíbam a prática do assédio nas instituições. Ainda, se faz necessário promover a comunicação interna e permitir reflexões sobre suas formas de organizar o trabalho. ${ }^{20}$
Pesquisa realizada sobre a compreensão de estudantes de enfermagem, com o uso da técnica do discurso do sujeito coletivo, não foram apontadas as principais características definidoras e diferenciais do assédio moral, que levam em consideração variáveis como tempo, repetição e intencionalidade ${ }^{13}$, mas sim as humilhações, os constrangimentos e as perseguições, de forma repetitiva, no ambiente de trabalho que desestabilizam o equilíbrio físico e emocional da vítima. ${ }^{19}$

A preparação para o mercado de trabalho, principalmente no âmbito da enfermagem, está diretamente ligada a aspectos intrínsecos da profissão, uma vez que o enfermeiro se forma "chefe" de equipe, ou seja, se torna responsável, como integrante da equipe de saúde, por participar na elaboração, execução e avaliação da programação de saúde, dos planos assistenciais de saúde, participação em projetos de construção ou reforma de unidades de internação entre outras providências $^{7}$ assumindo o papel de gestor, que abrange além de recursos humanos, recursos materiais e valores pessoais.

Nesse sentido, as intervenções necessárias para criar um ambiente de trabalho livre das situações de assédio moral, passam pela formulação de alta gerência, aspectos políticos e sociais que são imprescindíveis para lapidar as questões éticas ligadas à dignidade humana, que vão 
desde esclarecimentos e sensibilização da classe até a adoção de políticas preventivas de violência nas relações sociolaborais.

Compreender as emoções tristes, os mecanismos de defesa e de negação presentes no assédio moral, são fundamentais para que se evite a dualidade que muitos definem por "fingimento", tidos como naturais, inatas e irracionais. ${ }^{14}$ Tais situações podem influenciar diretamente o desempenho laboral, a saúde e o estado emocional dos enfermeiros. ${ }^{16}$ As repercussões à vítima podem ser o isolamento e, em alguns casos, levar ao consumo de álcool ou outras drogas, em pedir demissão ou ser demitido, inclusive por insubordinação. ${ }^{17}$

Aspectos voltados para as repercussões na saúde do enfermeiro apontam para os distúrbios psicossomáticos onde se incluem: depressão; estresse; baixa estima; síndrome de burnout; insônia; fadiga; problemas gástricos; distúrbios cardiovasculares; e, em casos extremos, o suicídio. ${ }^{18}$ Nessa seara, volta-se a atenção à saúde do enfermeiro, onde o profissional fica extremamente desprotegido, exposto às repercussões destrutivas, tanto no ambiente de trabalho, quanto no ambiente familiar, acometido de tristeza extrema, buscando o isolamento social.

Dentre as repercussões do assédio moral na saúde do enfermeiro, a maior preocupação da enfermagem do trabalho, em relação à saúde do profissional, é a identificação do agravo antes que se torne um problema disseminado por seus pares, para que seja desconstruída a imagem de normalidade entre os profissionais envolvidos.

\section{CONCLUSÃO}

Após a análise dos trabalhos pesquisados, percebe-se que dentre os principais aspectos do assédio moral, o que mais guarda relação com o labor do enfermeiro são os de cunho organizacional, em decorrência da estrutura hierárquica rígida presente em seu ambiente laboral, abrangendo as relações sociolaborais normativas. Destacam-se as variáveis "tempo escasso e repetição". Percebe-se ainda a necessidade de pesquisas sobre o assunto na área do direito com ênfase na atuação do enfermeiro, a fim de trazer para o campo objetivo a subjetividade que envolve o assédio moral, dirimindo os agravos à saúde do profissional.

Diante do exposto, traçando paralelos entre o assédio moral e o trabalho da enfermagem, constata-se que o ambiente laboral pode ser psicologicamente insalubre, permeado de incertezas, escassez de recursos humanos e materiais, o que favorecem as tensões emocionais que conduzem ao adoecimento psicossomático. Além das questões que envolvem o trabalho em si, existem fatores socioculturais que podem agravar a saúde mental desses trabalhadores, 
como por exemplo, situações de estresse geradas pela rotina, somadas à violência visível e invisível presentes no cotidiano.

\section{REFERÊNCIAS}

1- Margarida B. Assédio moral: trabalho, doenças e morte. In: Seminário:

Compreendendo o assédio moral no ambiente de trabalho [Internet]; 2010; São Paulo. São Paulo: Fundacentro; 2013 [citado em 10 ago 2015]. p. 13-26. Disponível em: http://assediomoral.paginas.ufsc.br/files/2013/ 03/Seminario-Combate-AMT-Fundacentro2013.pdf

2- Soares A. As origens do conceito de assédio moral no trabalho. Rev Bras Saúde Ocup. [Internet]. 2012 [citado em 13 jul 2018]; 37(126):284-286. Disponível em: http://www.scielo.br/pdf/rbso/v37n126/a09v3 7n126.pdf

3- Leymann H, Gustafsson A.

Självmordsfabriken [Resumo]. [Internet]. Estocolmo: Norstedts Juridik; 1998 [citado em 13 jul 2018]. Disponível em: http://www.mobbingportal.com/leymanncomingsoon.html 4- Barreto MMS. Violência, saúde e trabalho: uma jornada de humilhações. 3ed. São Paulo: EDUC; 2013. 5- Krug EG, Dahlberg LL, Mercy JA, Zwi AB, Lozano R, editores. Relatório mundial sobre violência e saúde [Internet]. Genebra: Organização Mundial da Saúde; 2002 [citado em 13 jul 2018]. Disponível em: https://www.opas.org.br/wpcontent/uploads/2015/09/relatorio-mundialviolencia-saude.pdf 6- Hirigoyen MF. Assédio moral: a violência perversa no cotidiano. 15ed. Rio de Janeiro: Bertrand Brasil; 2014.

7- Presidência da República (Brasil). Lei ${ }^{\circ}$ 7498, de 25 de junho de 1986. Dispõe sobre a regulamentação do exercício da enfermagem, e dá outras providências [Internet]. D.O.U., Brasília, DF, 26 jun 1986 [citado em 13 jul 2018]. Disponível em: https://presrepublica.jusbrasil.com.br/legislac ao/128195/lei-7498-86

8- Lima GHA, Sousa SMA. Violência psicológica no trabalho da enfermagem. Rev Bras Enferm. [Internet]. set/out 2015 [citado em 13 jul 2018]; 68(5):817-23. Disponível em:

http://www.scielo.br/pdf/reben/v68n5/0034-

7167-reben-68-05-0817.pdf

9- Costa ICP, Costa SFG, Andrade CG, Oliveira RC, Abrão FMS, Silva CRL.

Produção científica acerca de assédio moral em dissertações e teses no cenário brasileiro. Rev Esc Enferm USP. [Internet]. 2015 [citado em 13 jul 2018]; 49(2):267-276. Disponível em:

http://www.scielo.br/pdf/reeusp/v49n2/pt_008 0-6234-reeusp-49-02-0267.pdf

10- Fontes KB, Pelloso SM, Carvalho MDB. Tendência dos estudos sobre assédio moral e trabalhadores de enfermagem. Rev Gaúcha Enferm. [Internet]. 2011 [citado em 13 jul 2018]; 32(4):815-22. Disponível em: http://www.scielo.br/pdf/rgenf/v32n4/v32n4a 24.pdf

11- Glina DMR, Soboll LA. Intervenções em assédio moral no trabalho: uma revisão da literatura. Rev Bras Saúde Ocup. [Internet]. 2012 [citado em 13 jul 2018]; 37(126):26983. Disponível em: http://www.scielo.br/pdf/rbso/v37n126/a08v3 7n126.pdf

12- Lima LG, Pereira RP, Oliveira PJ, Brasileiro ME. Assédio moral e coping: atuação da enfermagem do trabalho. Rev Eletrônica Enferm CEEN [Internet]. jan-jul 2013 [citado em 05 jan 2013]; 5(5):1-11. Disponível em:

http://www.cpgls.pucgoias.edu.br/8mostra/Ar tigos/SAUDE\%20E\%20BIOLOGICAS/Ass\% C3\%A9dio\%20Moral\%20e\%20Coping\%20at ua\%C3\%A7\% $3 \%$ A3o\%20da\%20enfermage m\%20do\%20trabalho.pdf

13- Gouveia EML, Costa SFG, Leite ALT, Souto MC, Cahú GPR, Fonseca LCT.

Assédio moral: compreensão de estudantes de enfermagem. Rev Enferm UERJ. [Internet]. 2012 [citado em 13 jul 2018]; 20(2):161-6. Disponível em: http://www.epublicacoes.uerj.br/index.php/enfermagemuer j/article/view/4014/2780 
14- Barreto M, Heloani R. Violência, saúde e trabalho: a intolerância e o assédio moral nas relações laborais. Serv Soc Soc. [Internet]. jul/set 2015 [citado em 13 jul 2018]; 123:544561. Disponível em:

http://www.scielo.br/pdf/sssoc/n123/01016628-sssoc-123-0544.pdf

15- Fontes KB, Santana RG, Pelloso SM,

Carvalho MDB. Fatores associados ao assédio moral no ambiente laboral do enfermeiro. Rev Latinoam Enferm. [Internet]. maio/jun 2013 [citado em 13 jul 2018]; 21(3):[7 telas].

Disponível em:

http://www.scielo.br/pdf/rlae/v21n3/pt_01041169-rlae-21-03-0758.pdf 16- Cahú GRP, Costa SFG, Costa ICP, Batista PSS, Batista JBV. Situações de assédio moral vivenciadas por enfermeiros no ambiente de trabalho. Acta Paul Enferm. [Internet]. 2014 [citado em 13 jul 2018]; 27(2):151-156. Disponível em: http://www.scielo.br/pdf/ape/v27n2/01032100-ape-27-02-0151.pdf

17- Lisboa MTL. Assédio moral no trabalho de enfermagem [editorial]. Cogitare Enferm. [Internet]. 2010 [citado em 13 jul 2018];

15(1):9-11. Disponível em: https://revistas.ufpr.br/cogitare/article/view/1 7137/11280

18- Santos SIL, Andrade CG, Costa ICP, Santos KFO, Costa SFG, França JRFS. Assédio moral no âmbito da enfermagem: revisão integrativa da literatura. Cogitare Enferm. [Internet]. 2014 [citado em 13 jul 2018]; 19(1):159-65. Disponível em: https://revistas.ufpr.br/cogitare/article/view/3 5975/22183

19- Andrade CG, Leão JDM, Costa ICP, Brito FM, Santos KFO, Costa SFG. Assédio moral na atenção básica segundo os profissionais de enfermagem. Trab Educ Saúde [Internet]. 2015 [citado em 13 jul 2018]; 13(suppl1):7790. Disponível em: http://www.scielo.br/pdf/tes/v13s1/19817746-tes-13-s1-0077.pdf 20- Pereira IV. Assédio moral nas relações de trabalho de docentes-enfermeiros: sob a ótica da organização do trabalho [Tese]. Rio de Janeiro: Universidade Federal do Rio de Janeiro; 2011.
RECEBIDO: 15/10/2017

APROVADO: $27 / 12 / 2017$

PUBLICADO: 07/2018 